Check for updates

Cite this: RSC Adv., 2019, 9, 21438

9th May 2019

Accepted 2nd July 2019

DOI: $10.1039 / \mathrm{c} 9 \mathrm{ra03487 \textrm {k }}$

rsc.li/rsc-advances

\section{Rational design of functionalized covalent organic frameworks and their performance towards $\mathrm{CO}_{2}$ capture $\uparrow$}

\author{
Shuhao An, Ting Xu, Changjun Peng, (D) * Jun Hu (D) and Honglai Liu* \\ We describe the design and synthesis of two new functionalized covalent organic frameworks, named Cz- \\ COF and Tz-COF, by using monomers containing carbazole and benzobisthiazole as building blocks. The \\ resultant materials possess high crystallinity, permanent porosities as well as abundant heteroatom \\ activated sites in the framework. As solid adsorbents, both COFs exhibit excellent $\mathrm{CO}_{2}$ uptake $(11.0 \mathrm{wt} \%$ \\ for $\mathrm{Cz}$-COF and 15.4 wt\% for Tz-COF), high adsorption selectivity for $\mathrm{CO}_{2}$ over $\mathrm{N}_{2}$ and good recyclability.
}

\section{Introduction}

Covalent organic frameworks (COFs) ${ }^{1}$ with periodically ordered structures are a new emerging type of porous crystalline material, and have gained great attention in recent years. ${ }^{2-4}$ Owing to their features of robust framework, inherent porosity and tailormade functionalities, COFs have recently been seen as a new porous platform for extensive applications such as gas storage and separation, ${ }^{5-7}$ optoelectronics, ${ }^{8-10}$ catalysis, ${ }^{11-13}$ and chemical sensor. ${ }^{14-16}$ Thus far, in order to achieve excellent performance, a pore channel post-modification strategy has been seen as an effective means of introducing various functional moieties to modify the surface properties of the COF skeleton. ${ }^{17-20}$ However, this method tends to reduce the intrinsic porosity and crystallinity of the materials aiming to afford a high density of functional groups, and also suffers from the cleavage of grafted parts during recycling. Correspondingly, the direct construction of functionalized COFs by pre-designed monomers will reduce multistep synthetic procedure and allow the in situ introduced active sites to be more evenly dispersed in the framework..$^{21,22}$ Due to the solubility and geometric symmetry of building blocks have to be taken into account, the development of functionalized COFs still remains difficult and it is therefore strongly desired based on this method.

On the other hands, with rapid industrialization development and the progress of human society, the continuous emission of carbon dioxide $\left(\mathrm{CO}_{2}\right)$ in the atmosphere has become a massive global problem. For this reason, developing effective technologies and strategies to effectively capture $\mathrm{CO}_{2}$ and alleviate this predicament is both challenging and urgent. ${ }^{23}$

State Key Laboratory of Chemical Engineering and School of Chemistry \& Molecular Engineering, East China University of Science and Technology, Shanghai, 200237, China.E-mail: cjpeng@ecust.edu.cn; hlliu@ecust.edu.cn

$\dagger$ Electronic supplementary information (ESI) available. See DOI: 10.1039/c9ra03487k
Carbon capture and sequestration (CCS) technology is considered an economical and effective way to mitigate the trend of global warming. ${ }^{24-27}$ The development of novel nanoporous materials like metal-organic frameworks $(\mathrm{MOFs})^{28}$ and porous organic polymers (POPs), ${ }^{29,30}$ has shown particular promise for CCS because of their cost-effective physical adsorption process, high efficiency and facile recyclability. Remarkably, various $\mathrm{CO}_{2}$-philic moieties including triazine, ${ }^{31}$ carbazole $^{32}$ or benzothiazole ${ }^{33}$ have been incorporated into the polymeric networks to enhance the interaction between the material surfaces and $\mathrm{CO}_{2}$ molecules, consequently exhibiting excellent performance towards $\mathrm{CO}_{2}$ capture. Thus, rationally design and synthesis of functionalized COFs consist of these moieties not only extend the library of COFs but also investigate COF-based adsorbents for efficient $\mathrm{CO}_{2}$ capture.

Herein, we contribute to describe the synthesis and $\mathrm{CO}_{2}$ gas adsorption properties of two new functionalized COFs, Cz-COF and Tz-COF, prepared by using monomers containing carbazole $(\mathrm{Cz})$ and benzobisthiazole $(\mathrm{Tz})$ as building blocks. The crystalline structures and porous properties of obtained COFs are systematically examined through powder X-ray diffraction and nitrogen adsorption-desorption experiments. Most importantly, because of their permanent porosities and abundant heteroatom ( $\mathrm{N}$ or $\mathrm{S}$ ) polar sites, both COFs show excellent $\mathrm{CO}_{2}$ uptake, high adsorption selectivity for $\mathrm{CO}_{2}$ over $\mathrm{N}_{2}$ and good recyclability at ambient conditions.

\section{Results and discussion}

Although monomers containing $\mathrm{Cz}$ and $\mathrm{Tz}$ were employed as the scaffolds for the construction of amorphous POPs towards applications such as $\mathrm{CO}_{2}$ adsorption ${ }^{33,34}$ and semiconductor materials, ${ }^{35}$ to the best of our knowledge, no previous example of crystalline COFs based on $\mathrm{Cz}$ and $\mathrm{Tz}$ has been reported. As shown in Scheme 1, our strategy for preparing functionalized COFs involves imine-bond formation reactions together with 

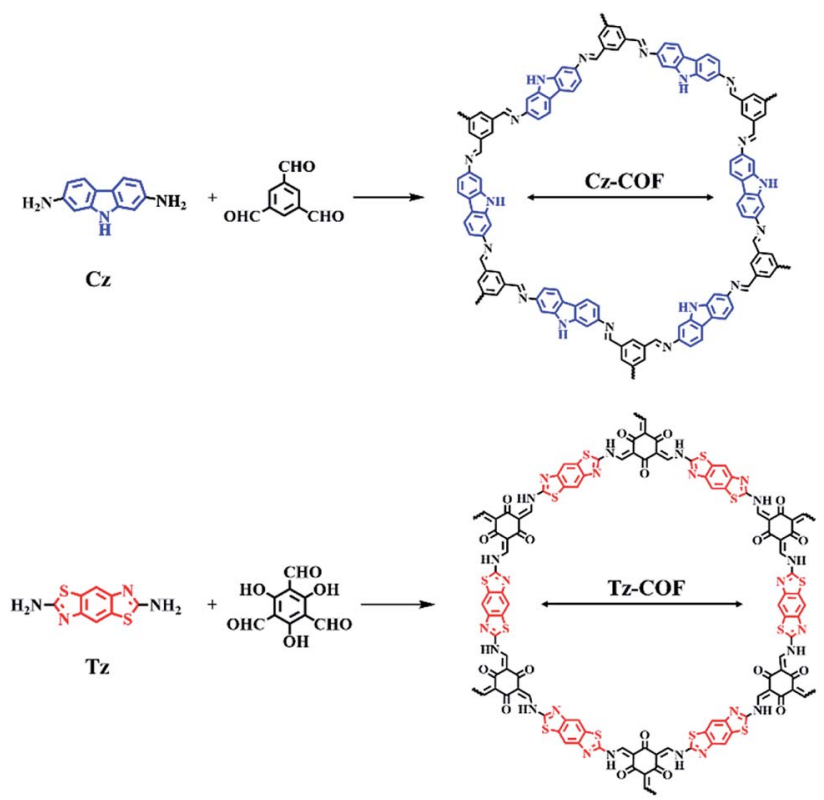

Scheme 1 Schematic representation of the synthesis of functionalized COFs.

typical $\left[\mathrm{C}_{3}+\mathrm{C}_{2}\right]$ schemes. After screening reaction conditions, $\mathrm{Cz}$-COF was synthesized in dioxane/mesitylene/3 M AcOH (15/ $15 / 2 \mathrm{v} / \mathrm{v}$ ) at $120{ }^{\circ} \mathrm{C}$ for 3 days and obtained as yellow solid in $85 \%$ isolated yield. Tz-COF was synthesized in dioxane/3 M $\mathrm{AcOH}(5 / 1 \mathrm{v} / \mathrm{v})$ at $120{ }^{\circ} \mathrm{C}$ for 3 days and obtained as red solid in $84 \%$ isolated yield. These solid products were insoluble in water and common organic solvents such as tetrahydrofuran (THF), $\mathrm{N}, \mathrm{N}$-dimethylformamide (DMF) and dimethyl sulfoxide (DMSO). Thermogravimetric analysis (TGA) further revealed that both COFs exhibited high thermal stability up to $400{ }^{\circ} \mathrm{C}$ (Fig. S3†).

The molecular structures of $\mathrm{Cz}-\mathrm{COF}$ and $\mathrm{Tz}-\mathrm{COF}$ were confirmed by Fourier transform infrared (FT-IR) spectroscopy and cross-polarization magic angle spinning (CP-MAS) ${ }^{13} \mathrm{C} \mathrm{NMR}$ spectroscopy. In the IR spectrum of $\mathrm{Cz}-\mathrm{COF}$ (Fig. S4 $\dagger$ ), the strong absorption peaks for $\mathrm{N}-\mathrm{H}\left(3405 \mathrm{~cm}^{-1}\right)$ and $\mathrm{C}-\mathrm{N}$ $\left(1234 \mathrm{~cm}^{-1}\right)$ indicated the presence of the carbazole moiety within the network, while a new characteristic stretching band for $\mathrm{C}=\mathrm{N}\left(1629 \mathrm{~cm}^{-1}\right)$ was observed. ${ }^{36}$ The IR spectrum of TzCOF (Fig. S5 $\dagger$ ) indicated total consumption of the monomer based on the disappearance of the $\mathrm{N}-\mathrm{H}$ absorption peaks of $\mathrm{Tz}$. Moreover, a strong peak at $1596 \mathrm{~cm}^{-1}$ arising from the $\mathrm{C}=\mathrm{C}$ stretching band present in the keto form. It should be noted that the $\mathrm{C}=\mathrm{O}$ peak of Tz-COF were merged with the $\mathrm{C}=\mathrm{C}$ stretching band at $1596 \mathrm{~cm}^{-1}$ as reported TpPa-1 and TpPa-2 $\mathrm{COF}^{37}{ }^{13} \mathrm{C}$ NMR spectrum of functionalized COFs also revealed the structures of their polymeric architectures very well (Fig. S6 and $\mathrm{S} 7 \dagger$ ). For Cz-COF, the peak at ca. 157 ppm corresponds to the carbon of the imine bonds $(\mathrm{C}=\mathrm{N})$. The two peaks at $c a .110 \mathrm{ppm}$ and $99 \mathrm{ppm}$ in $\mathrm{Cz}-\mathrm{COF}$ arise from the phenyl carbons ortho to the carbazole nitrogen substitution site. ${ }^{34}$ The Tz-COF in keto form was also confirmed by the peak at $c a$. $180 \mathrm{ppm}$ ascribed to typical ketone carbon $(\mathrm{C}=\mathrm{O})$. The phenyl carbons from the benzobisthiazole were located at $c a .144 \mathrm{ppm}$ and 128 ppm. ${ }^{33}$ The morphology of functionalized COFs was examined by scanning electron microscopy (SEM), in which Cz$\mathrm{COF}$ and Tz-COF exhibited different morphology: Cz-COF possessed spherical particle aggregation, whereas Tz-COF showed a large quantity of uniform nanofibers (Fig. S8†).

The powder X-ray diffraction (PXRD) analysis was subsequently used to investigate the crystallinity of the as-synthesized two COFs (Fig. 1). Cz-COF exhibited an intense peak at $3.6^{\circ}$ and other three minor peaks at $6.4^{\circ}, 7.4^{\circ}$ and $9.7^{\circ}$, which correspond to the reflection from the (100), (110), (200) and (210) planes, respectively (Fig. 1a, red dot). The periodicity of the $2 \mathrm{D}$ sheets as a result of $\pi-\pi$ interaction can also be inferred from the broad peak at $c a .26 .9^{\circ}$, which is ascribed to the reflection from (001) plane. $^{38}$ The diffraction pattern of Tz-COF exhibited signals at $3.8^{\circ}, 6.2^{\circ}, 7.2^{\circ}, 9.6^{\circ}$ and $26.7^{\circ}$ that were assigned to the (100), (110), (200), (210) and (001) planes, respectively (Fig. 1c, red dot). Two types of extended structures based on eclipsed (AA) and staggered $(\mathrm{AB})$ stacking models in the space group P6 were generated for both COFs by the Materials Studio software package and then simulated their powder PXRD patterns (Fig. 1a and c, pink and green curve, respectively). The calculated PXRD patterns based on AA stacking model shows excellent agreement with experimental results in terms of peak positions and intensities for both COFs (Fig. 1a and c, blue curve). The Pawley refinements were further conducted and yielded the unit cell parameters with good agreement factors $(a=b=28.79 \AA$, $c=$ $3.51 \AA$, $R_{\mathrm{WP}}=5.63 \%, R_{\mathrm{P}}=3.30 \%$ for Cz-COF and $a=b=28.55 \AA$, $c=3.78 \AA, R_{\mathrm{WP}}=4.79 \%, R_{\mathrm{P}}=9.23 \%$ for Tz-COF). On the basis of these results, Fig. $1 \mathrm{~b}$ and $\mathrm{d}$ illustrate the eclipsed AA stacking structures of Cz-COF and Tz-COF, respectively.

To investigate the permanent porosities of the functionalized COFs, nitrogen gas adsorption-desorption isotherms were measured at $77 \mathrm{~K}$. The fresh sample was degassed at $120^{\circ} \mathrm{C}$ and $1 \times 10^{-5}$ Torr for $12 \mathrm{~h}$ prior to porosity measurement. As shown in Fig. 2, activated Cz-COF and Tz-COF show a sharp uptake under low relative pressure, which reflects the presence of micropores. The step observed at $P / P_{0}=0.10-0.20$ indicates pore condensation in mesopores with a narrow distribution. ${ }^{39}$ The Brunauer-Emmett-Teller (BET) surface areas of the activated COFs were calculated to be $871 \mathrm{~m}^{2} \mathrm{~g}^{-1}$ for $\mathrm{Cz}-\mathrm{COF}$ and $1439 \mathrm{~m}^{2} \mathrm{~g}^{-1}$ for Tz-COF. The total pore volumes were evaluated at $P / P_{0}=0.99$ to be $V_{\mathrm{p}}=0.72 \mathrm{~cm}^{3} \mathrm{~g}^{-1}$ for $\mathrm{Cz}-\mathrm{COF}$ and $1.18 \mathrm{~cm}^{3}$ $\mathrm{g}^{-1}$ for Tz-COF. The pore size distributions (PSD) based on the nonlocal density functional theory (NLDFT) exhibit two dominant pore diameters of $1.2 \mathrm{~nm}$ and $2.0 \mathrm{~nm}$ for $\mathrm{Cz}-\mathrm{COF} ; 0.7 \mathrm{~nm}$ and $2.1 \mathrm{~nm}$ for Tz-COF (Fig. 2, insets). The difference between the PSD results with pore width predicted from the eclipsed AA stacking model (2.3 nm for Cz-COF; $2.6 \mathrm{~nm}$ for Tz-COF) mainly due to imperfect solid-state stacking of the two-dimension (2D) sheets in the framework that cannot be identified by PXRD studies as reported for many $2 \mathrm{D}$ COFs..$^{\mathbf{4 0 4 1}}$

In view of the fact that the functionalized COFs possess ordered structures, excellent porous characteristics, and in situ abundant $\mathrm{CO}_{2}$-philic heteroatom ( $\mathrm{N}$ or $\mathrm{S}$ ) sites among the pore wall, which promote us to investigate their $\mathrm{CO}_{2}$ uptake capacities. The $\mathrm{CO}_{2}$ adsorption isotherms were measured up to $1 \mathrm{bar}$ 
(a)
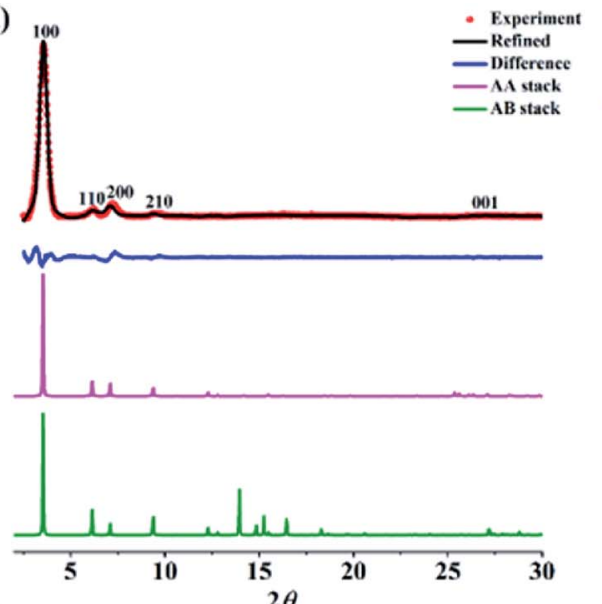

(c)

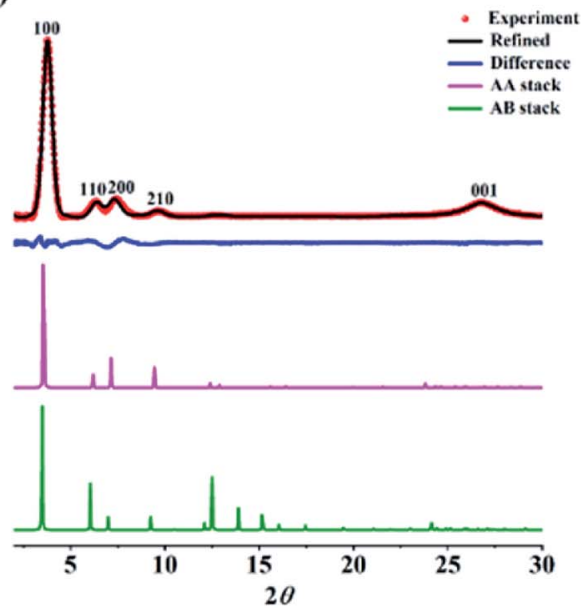

(b)

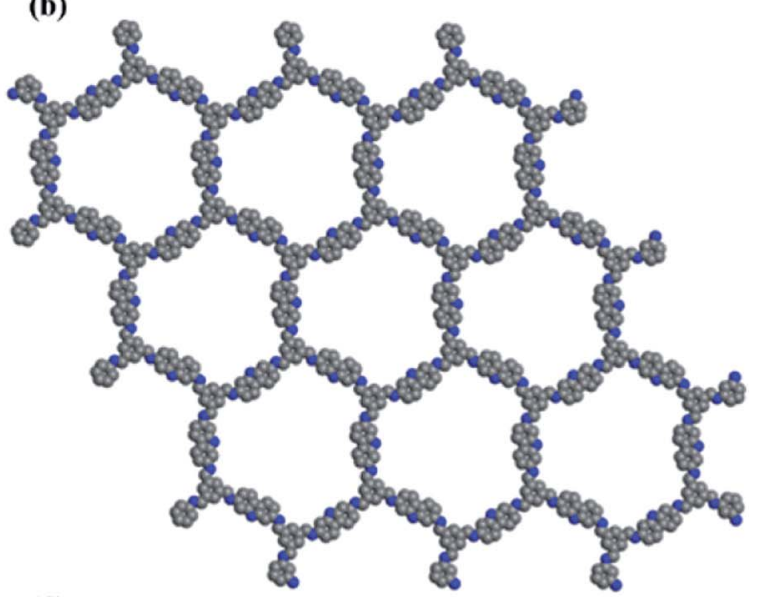

(d)

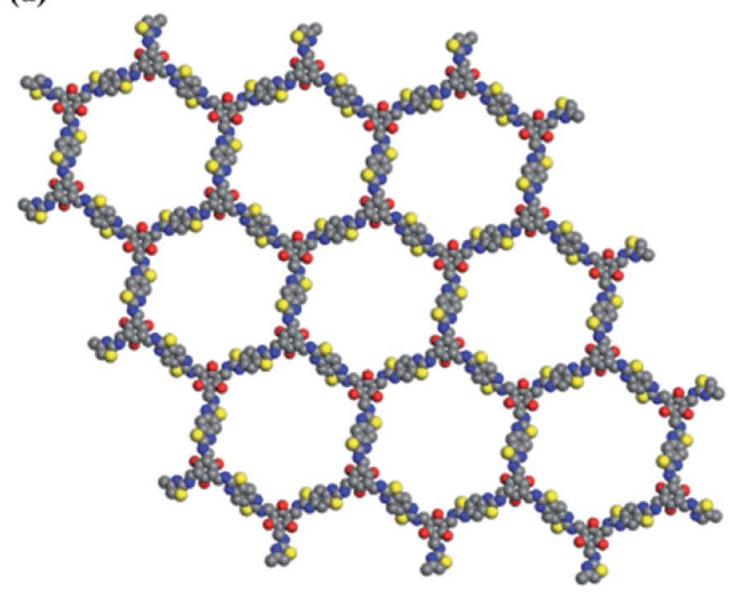

Fig. 1 PXRD patterns of (a) Cz-COF and (c) Tz-COF: experimental (red), Pawley refined (black), difference between experimental and calculated data (blue), calculated for AA-stacking (pink), and calculated for AB-stacking (green). Space filling models of the (b) Cz-COF and (d) Tz-COF in AA.

at both $273 \mathrm{~K}$ and $298 \mathrm{~K}$ for both COFs (Fig. 3a and b). Remarkably, Cz-COF and Tz-COF show uptakes of $2.5 \mathrm{mmol} \mathrm{g}^{-1}$ (11.0 wt\%) and $3.5 \mathrm{mmol} \mathrm{g}^{-1}(15.4 \mathrm{wt} \%)$, respectively, at $273 \mathrm{~K}$ (Table 1). The $\mathrm{CO}_{2}$ adsorption capacity of Tz-COF is not only higher than that of many previously reported COFs such as COF-103 (7.6 wt $\left.\%, S_{\mathrm{BET}}=3530 \mathrm{~m}^{2} \mathrm{~g}^{-1}\right),{ }^{5}$ ILCOF-1 $\left(6.0 \mathrm{wt} \%, S_{\mathrm{BET}}\right.$ $\left.=2723 \mathrm{~m}^{2} \mathrm{~g}^{-1}\right)^{42}$ and TDCOF-5 $\left(9.2 \mathrm{wt} \%, S_{\mathrm{BET}}=2497 \mathrm{~m}^{2} \mathrm{~g}^{-1}\right)^{43}$ even though they have a much higher surface area, but also comparable to the reported excellent amorphous porous organic polymers like benzimidazole-linked polymers BILP-1 $(18.8 \mathrm{wt} \%){ }^{44}$ microporous polycarbazole CPOP-1 $(21.2 \mathrm{wt} \%)^{32}$ and microporous polyaminal networks PAN-2 $(17.7 \mathrm{wt} \%)^{45}$ under the same conditions (Table S1†). Previous work has shown that heteroatom sites may have an important influence
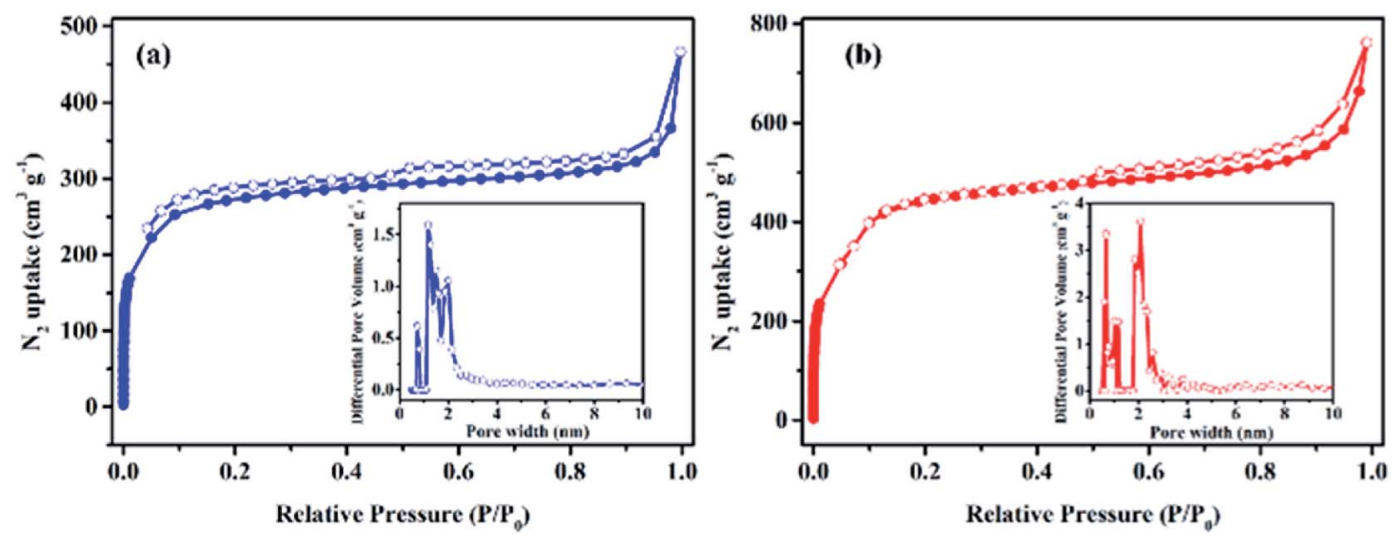

Fig. 2 Nitrogen gas adsorption and desorption isotherms for (a) Cz-COF and (b) Tz-COF. Insets: pore size distributions. 
(a)

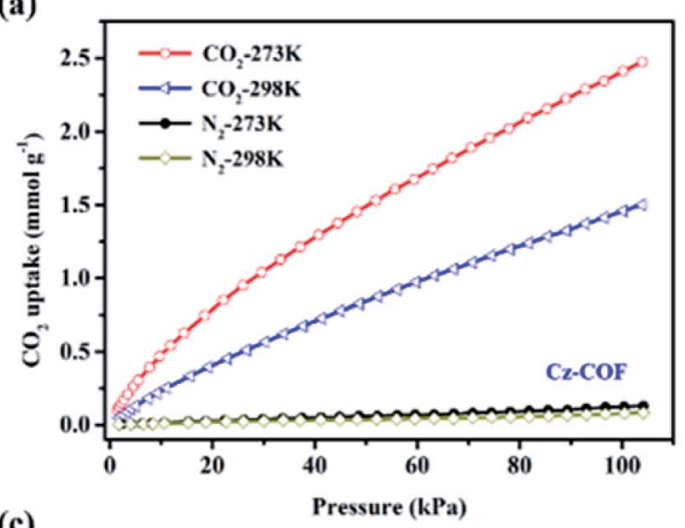

(c)

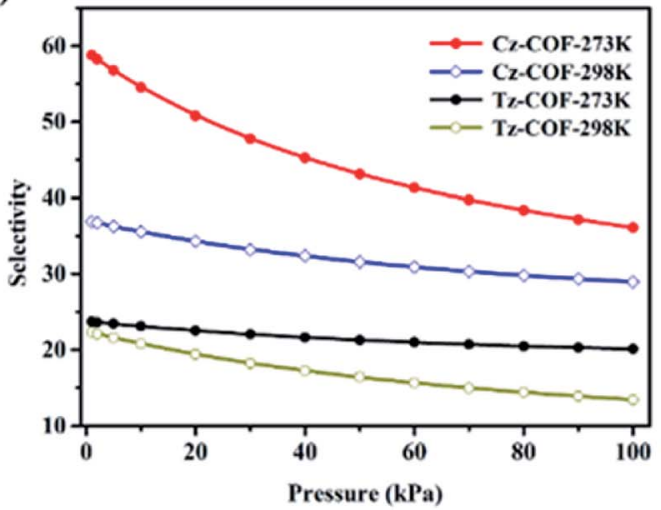

(b)

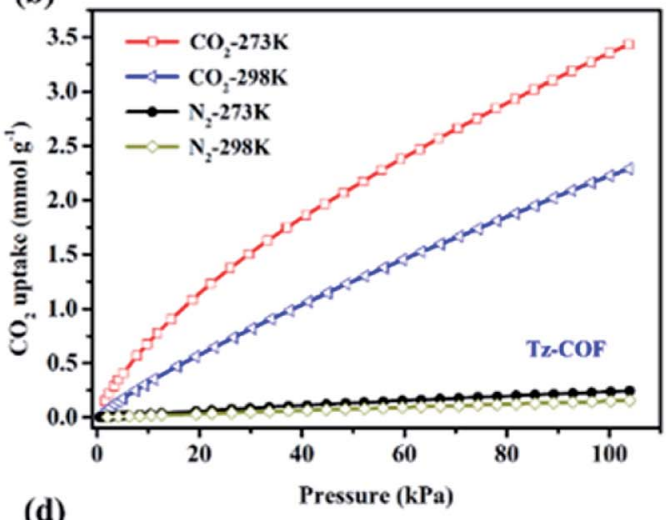

(d)

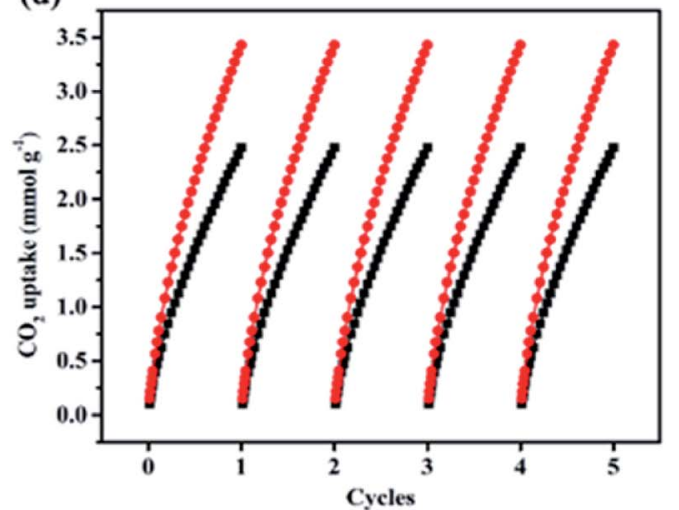

Fig. $3 \mathrm{CO}_{2}$ and $\mathrm{N}_{2}$ adsorption isotherms for (a) $\mathrm{Cz}$-COF and (b) Tz-COF measured at $273 \mathrm{~K}$ and $298 \mathrm{~K}$, respectively. (c) The selectivity of functionalized COFs for $\mathrm{CO}_{2}$ over $\mathrm{N}_{2}$ obtained from the IAST method. (d) Cyclic $\mathrm{CO}_{2}$ adsorption for functionalized COFs (black line, Cz-COF; red line, Tz-COF).

on $\mathrm{CO}_{2}$ adsorption besides the contribution of porous properties. ${ }^{46}$ To obtain a better understanding, we then calculated the isosteric heats of adsorption $\left(Q_{\text {st }}\right)$ for both functionalized COFs by fitting the $\mathrm{CO}_{2}$ adsorption isotherms obtained from different temperature and applying the Clausius-Clapeyron equation (Fig. S9 $\dagger$ ). At low adsorption values, $Q_{\text {st }}$ was calculated to be $20 \mathrm{~kJ} \mathrm{~mol}^{-1}$ for $\mathrm{Cz}-\mathrm{COF}$ and $22 \mathrm{~kJ} \mathrm{~mol}^{-1}$ for Tz-COF, suggesting a strong dipole-quadrupole interaction between the COFs framework and $\mathrm{CO}_{2}$ molecules, which is similar to reported functionalized POPs ${ }^{32}$ and COFs. ${ }^{41}$

The selectivity is another key parameter for COF-based adsorbents in gas separation field. We subsequently performed the $\mathrm{N}_{2}$ adsorption at both 273 and $298 \mathrm{~K}$ ( 1 bar) to examine the selective adsorption for $\mathrm{CO}_{2}$ over $\mathrm{N}_{2}$ (Fig. 3a and b). On the basis of Ideal Adsorption Solution Theory (IAST) method ${ }^{47}$ the $\mathrm{CO}_{2} / \mathrm{N}_{2}(10: 85 \mathrm{v}: \mathrm{v})$ selectivity for the functionalized COFs were calculated to be 36 for Cz-COF and 20 for Tz$\mathrm{COF}$ at $273 \mathrm{~K}$ and 1 bar (Fig. $3 \mathrm{c}$ ). This value of $\mathrm{Cz}$-COF surpasses reported TpPa-COF $(32)^{48}$ or $\left[\mathrm{EtNH}_{2}\right]_{50}-\mathrm{H}_{2} \mathrm{P}-\mathrm{COF}(17)^{18}$ and is lower than the high values of micorporous organic polymers including azo-linked polymer azo-POP-2 (130), ${ }^{49}$ aromatic heterocyclic polymer Py-1 (117) ${ }^{50}$ and PPN-6-SO ${ }_{3} \mathrm{H}(150,295 \mathrm{~K})^{51}$ (Table S1†). At $298 \mathrm{~K}$, the $\mathrm{CO}_{2} / \mathrm{N}_{2}$ selectivity for $\mathrm{Cz}-\mathrm{COF}$ and TzCOF decrease to 29 and 13, respectively. Moreover, the selectivity values for the functionalized COFs were further calculated to be 44 for Cz-COF and 24 for Tz-COF at $273 \mathrm{~K}$ using the ratio of the initial slopes of the $\mathrm{CO}_{2}$ and $\mathrm{N}_{2}$ adsorption isotherms (Fig. S10†), which is consistent with those obtained from IAST method. Interestingly, at $298 \mathrm{~K}$, the $\mathrm{CO}_{2} / \mathrm{N}_{2}$ selectivity of Cz-COF and Tz-COF remain at a good level and reach 28 and 21, respectively. Furthermore, five times adsorption-desorption cycle was performed to test the recyclability of the functionalized COFs. As shown in Fig. 3d, there was no apparent loss of uptake amount in each cycling test for both COFs, revealing the good sustainability for functionalized COFs in $\mathrm{CO}_{2}$ capture process.

Table 1 The characteristics of functionalized COFs in this work

\begin{tabular}{|c|c|c|c|c|c|}
\hline COFs & $S_{\text {BET }}\left(\mathrm{m}^{2} \mathrm{~g}^{-1}\right)$ & $V_{\text {total }}{ }^{a}\left(\mathrm{~cm}^{3} \mathrm{~g}^{-1}\right)$ & $\mathrm{CO}_{2}$ uptake $^{b}\left(\mathrm{mmol} \mathrm{g}^{-1}\right) 273 \mathrm{~K} / 298 \mathrm{~K}$ & $Q_{\mathrm{st}}\left(\mathrm{kJ} \mathrm{mol}^{-1}\right)$ & Selectivity $^{c} 273 \mathrm{~K} / 298 \mathrm{~K}$ \\
\hline $\mathrm{Cz}-\mathrm{COF}$ & 871 & 0.72 & $2.5 / 1.5$ & 20 & $36 / 28$ \\
\hline Tz-COF & 1439 & 1.18 & $3.5 / 2.3$ & 22 & $20 / 12$ \\
\hline
\end{tabular}

${ }^{a}$ Total volumes calculated at $P / P_{0}=0.99 .{ }^{b}$ Measured at the pressure of 1 bar. ${ }^{c}$ IAST selectivity (1 bar) for $\mathrm{CO}_{2} / \mathrm{N}_{2}(10: 85 \mathrm{v}: \mathrm{v})$. 


\section{Conclusions}

In conclusion, we have synthesized two new functionalized COFs, Cz-COF and Tz-COF, by using monomers containing carbazole and benzobisthiazole as building blocks. Due to their characterization of high crystallinity, permanent porosities as well as abundant heteroatom activated sites in the framework, both COFs exhibit excellent $\mathrm{CO}_{2}$ uptake $\mathbf{1 1 . 0} \mathrm{wt} \%$ for $\mathrm{Cz}-\mathrm{COF}$ and $15.4 \mathrm{wt} \%$ for Tz-COF), high adsorption selectivity for $\mathrm{CO}_{2}$ over $\mathrm{N}_{2}$ and good recyclability. We expect that these two functionalized COFs successfully prepared in this study not only extend the library of COFs but also inspire us to investigate their potential application in semiconductor material and photocatalyst.

\section{Conflicts of interest}

There are no conflicts to declare.

\section{Acknowledgements}

The research was supported by the National Natural Science Foundation of China (no. 91334203, 21476070) and the 111 Project of Ministry of Education of China (no. B08021).

\section{Notes and references}

1 A. P. Cote, A. I. Benin, N. W. Ockwig, M. O'keeffe, A. J. Matzger and O. M. Yaghi, Science, 2005, 310, 1166-1170.

2 X. Feng, X. Ding and D. Jiang, Chem. Soc. Rev., 2012, 41, 6010-6022.

3 S. Y. Ding and W. Wang, Chem. Soc. Rev., 2013, 42, 548-568.

4 M. S. Lohse and T. Bein, Adv. Funct. Mater., 2018, 28, 1705553.

5 H. Furukawa and O. M. Yaghi, J. Am. Chem. Soc., 2009, 131, 8875-8883.

6 Y. Zeng, R. Zou and Y. Zhao, Adv. Mater., 2016, 28, 28552873.

7 Y. Pramudya and J. L. Mendoza-Cortes, J. Am. Chem. Soc., 2016, 138, 15204-15213.

8 S. Wan, J. Guo, J. Kim, H. Ihee and D. Jiang, Angew. Chem., Int. Ed., 2008, 120, 8958-8962.

9 X. Feng, L. Liu, Y. Honsho, A. Saeki, S. Seki, S. Irle, Y. Dong, A. Nagai and D. Jiang, Angew. Chem., Int. Ed., 2012, 124, 2672-2676.

10 M. Dogru and T. Bein, Chem. Commun., 2014, 50, 5531-5546.

11 S. Y. Ding, J. Gao, Q. Wang, Y. Zhang, W. G. Song, C. Y. Su and W. Wang, J. Am. Chem. Soc., 2011, 133, 19816-19822.

12 Q. Fang, S. Gu, J. Zheng, Z. Zhuang, S. Qiu and Y. Yan, Angew. Chem., Int. Ed., 2014, 126, 2922-2926.

13 S. Lu, Y. Hu, S. Wan, R. McCaffrey, Y. Jin, H. Gu and W. Zhang, J. Am. Chem. Soc., 2017, 139, 17082-17088.

14 W. Li, C. X. Yang and X. P. Yan, Chem. Commun., 2017, 53, 11469-11471.

15 S. Y. Ding, M. Dong, Y. W. Wang, Y. T. Chen, H. Z. Wang, C. Y. Su and W. Wang, J. Am. Chem. Soc., 2016, 138, 30313037.
16 Z. Li, N. Huang, K. H. Lee, Y. Feng, S. Tao, Q. Jiang, Y. Nagao, S. Irle and D. Jiang, J. Am. Chem. Soc., 2018, 140, 1237412377.

17 A. Nagai, Z. Guo, X. Feng, S. Jin, X. Chen, X. Ding and D. Jiang, Nat. Commun., 2011, 2, 536.

18 N. Huang, R. Krishna and D. Jiang, J. Am. Chem. Soc., 2015, 137, 7079-7082.

19 Q. Lu, Y. Ma, H. Li, X. Guan, Y. Yusran, M. Xue, Q. Fang, Y. Yan, S. Qiu and V. Valtchev, Angew. Chem., Int. Ed., 2018, 57, 6042-6048.

20 H. Guo, J. Wang, Q. Fang, Y. Zhao, S. Gu, J. Zheng and Y. Yan, CrystEngComm, 2017, 19, 4905-4910.

21 H. S. Xu, S. Y. Ding, W. K. An, H. Wu and W. Wang, J. Am. Chem. Soc., 2016, 138, 11489-11492.

22 G. Lin, H. Ding, R. Chen, Z. Peng, B. Wang and C. Wang, J. Am. Chem. Soc., 2017, 139, 8705-8709.

23 R. S. Haszeldine, Science, 2009, 325, 1647-1652.

24 M. E. Boot-Handford, J. C. Abanades, E. J. Anthony, M. J. Blunt, S. Brandani, N. Mac Dowell, J. R. Fernández, M. C. Ferrari, R. Gross and J. P. Hallett, Energy Environ. Sci., 2014, 7, 130-189.

25 M. Bui, C. S. Adjiman, A. Bardow, E. J. Anthony, A. Boston, S. Brown, P. S. Fennell, S. Fuss, A. Galindo and L. A. Hackett, Energy Environ. Sci., 2018, 11, 1062-1176.

26 Z. Li, X. Feng, Y. Zou, Y. Zhang, H. Xia, X. Liu and Y. Mu, Chem. Commun., 2014, 50, 13825-13828.

27 Y. F. Zhi, P. P. Shao, X. Feng, H. Xia, Y. M. Zhang, Z. Shi, Y. Mu and X. M. Liu, J. Mater. Chem. A, 2018, 6, 374-382.

28 Y. Lin, C. Kong, Q. Zhang and L. Chen, Adv. Energy Mater., 2017, 7, 1601296.

29 R. Dawson, E. Stöckel, J. R. Holst, D. J. Adams and A. I. Cooper, Energy Environ. Sci., 2011, 4, 4239-4245.

30 R. He, S. Cong, J. Wang, J. Liu and Y. Zhang, ACS Appl. Mater. Interfaces, 2019, 11, 4338-4344.

31 A. K. Sekizkardes, S. Altarawneh, Z. Kahveci, T. İslamoğlu and H. M. El-Kaderi, Macromolecules, 2014, 47, 8328-8334.

32 Q. Chen, M. Luo, P. Hammershøj, D. Zhou, Y. Han, B. W. Laursen, C. G. Yan and B. H. Han, J. Am. Chem. Soc., 2012, 134, 6084-6087.

33 V. S. P. K. Neti, X. Wu, P. Peng, S. Deng and L. Echegoyen, RSC Adv., 2014, 4, 9669-9672.

34 X. Zhu, S. M. Mahurin, S. H. An, C. L. Do-Thanh, C. Tian, Y. Li, L. W. Gill, E. W. Hagaman, Z. Bian and J. H. Zhou, Chem. Commun., 2014, 50, 7933-7936.

35 A. P. Katsoulidis, S. M. Dyar, R. Carmieli, C. D. Malliakas, M. R. Wasielewski and M. G. Kanatzidis, J. Mater. Chem. A, 2013, 1, 10465-10473.

36 M. Grigoras and N. C. Antonoaia, Eur. Polym. J., 2005, 41, 1079-1089.

37 S. Kandambeth, A. Mallick, B. Lukose, M. V. Mane, T. Heine and R. Banerjee, J. Am. Chem. Soc., 2012, 134, 19524-19527.

38 S. Dalapati, M. Addicoat, S. Jin, T. Sakurai, J. Gao, H. Xu, S. Irle, S. Seki and D. Jiang, Nat. Commun., 2015, 6, 7786.

39 Q. Fang, Z. Zhuang, S. Gu, R. B. Kaspar, J. Zheng, J. Wang, S. Qiu and Y. Yan, Nat. Commun., 2014, 5, 4503.

40 B. Lukose, A. Kuc and T. Heine, Chem.-Eur. J., 2011, 17, 2388-2392. 
41 Z. Li, Y. Zhi, X. Feng, X. Ding, Y. Zou, X. Liu and Y. Mu, Chem.-Eur. J., 2015, 21, 12079-12084.

42 M. G. Rabbani, A. K. Sekizkardes, Z. Kahveci, T. E. Reich, R. Ding and H. M. El-Kaderi, Chem.-Eur. J., 2013, 19, 33243328.

43 Z. Kahveci, T. Islamoglu, G. A. Shar, R. Ding and H. M. ElKaderi, CrystEngComm, 2013, 15, 1524-1527.

44 M. G. Rabbani and H. M. El-Kaderi, Chem. Mater., 2012, 24, 1511-1517.

45 G. Li, B. Zhang, J. Yan and Z. Wang, Macromolecules, 2014, 47, 6664-6670.
46 R. Dawson, D. J. Adams and A. I. Cooper, Chem. Sci., 2011, 2, 1173-1177.

47 A. L. Myers and J. M. Prausnitz, AIChE J., 1965, 11, 121-127. 48 H. Wei, S. Chai, N. Hu, Z. Yang, L. Wei and L. Wang, Chem. Commun., 2015, 51, 12178-12181.

49 H. A. Patel, S. H. Je, J. Park, D. P. Chen, Y. Jung, C. T. Yavuz and A. Coskun, Nat. Commun., 2013, 4, 1357.

50 Y. Luo, B. Li, W. Wang, K. Wu and B. Tan, Adv. Mater., 2012, 24, 5703-5707.

51 W. Lu, D. Yuan, J. Sculley, D. Zhao, R. Krishna and H. C. Zhou, J. Am. Chem. Soc., 2011, 133, 18126-18129. 